\title{
The magnetization of sediment cores from the eastern basin of the North Atlantic Ocean
}

\author{
M. J. KeEN* \\ Department of Geodesy and Geophysics, Cambridge University
}

(Received 7 March 1963)

\begin{abstract}
The magnetization of sediment from the eastern basin of the North Atlantic Ocean is due to magnetite. The variation of the directions of magnetization in cores from the abyssal plains depends upon the sedimentary features which are the result of turbidity current deposition. The change in the inclination in the cores from the abyssal hills and mountains which rise from, or which surround, the Iberia plain suggests that there may be an effect due to consolidation. The magnetic susceptibility of the sediment depends upon the amount of magnetite present and its size distribution. One test on one core suggests instability and no correlation has been found between the directions of magnetization of adjacent cores.
\end{abstract}

\section{INTRODUCTION}

THIS is an account of studies of the magnetization of cores of sediment collected from the eastern basin of the North Atlantic. They were collected on an expedition organized by members of the Department of Geodesy and Geophysics, Cambridge University, and the National Institute of Oceanography from R.R.S. Discovery II in 1958.

The studies were made to see whether it is possible to investigate the history of the Earth's magnetic field by using the remanent magnetization of deep-sea sediments. Conversely, changes in the Earth's field recorded in the sediment might lead to a method of correlating oceanic sediment cores. Studies of the magnetic properties of rocks have been made for the same purpose. These studies have been principally of changes in the directions of the remanent magnetization in rocks of ages which vary by tens of thousands or millions of years; the secular variation, which is known historically or known through investigations of archaeological material such as fired clays, is concerned with a time scale of the order of several hundreds of years. The rate of sedimentation of deep-sea sediments ranges from about $0.1 \mathrm{~cm}$ per thousand years in red clays to several $\mathrm{cm}$ per thousand years in sediments such as globigerina oozes and sediments where there was a large supply of continental detritus available. The magnetization of samples of sediment which have dimensions of the order of $1 \mathrm{~cm}$ can be measured so that the time scale of any field changes recorded in deep-sea sediments would be intermediate in range between that which may be recorded in continental rocks and that of the historically known, secular variation.

Studies of the magnetic properties of oceanic sediments have been made before

*Present address : Institute of Oceanography, Dalhousie University, Halifax, Nova Scotia. 
by MCNish and JoHnson (1939) and by JoHnson et al. (1948). Allied to the problems associated with oceanic sediments are those of varved clays and of artifically deposited sediments (IsING, 1943; GrANAR, 1959; GrIFFITHS et al., 1960; REES, 1961).

\section{METHODS}

The cores were obtained with piston corers. The corer body of one was made of stainless steel and the other of mild steel; lead weights and stainless steel core barrels were used. No effect of the mild steel body upon the magnetic properties of the sediment was noticed. The sediment was retained in a copper liner which fitted inside the main corer barrel and the ends of the liner were sealed with rubber bungs, after removal from the core barrel.

The liners were cut down their lengths into two parts, one of which was retained as a reference slice. The part from which samples were taken was held in a trackway made of slotted angle channels. Glass cylinders were pushed into the wet sediment at right angles to the length of the core; this direction was retained in the sample with a strip of paper with a line marked on it. The samples were sealed at the ends with paraffin wax and an epoxy resin. The absolute orientation of the samples is not known and therefore the declination of the remanent magnetization is not known absolutely, but in any one core all the cylinders have the same attitude one to another so that the change in declination from sample to sample can be found. Experiments with inclinometers showed that the corer falls vertically and therefore the inclination of the remanent magnetization is absolutely known.

The remanent magnetization was measured on an astatic magnetometer. The susceptibility was found on an a.c. bridge built by DR. M. FULLER and DR. R. GIRDLER. Thermomagnetic analyses were made using a modification of this bridge and with a Curie balance.

\section{THE LITHOLOGY OF THE SEDIMENTS}

One core was collected from one of the seamounts which rise to the west of the Biscay abyssal plain, and all the others described here were obtained from the Iberia abyssal plain and from the hills and mountains which rise out of it or surround it. The part of the Iberia plain from which most of the cores were taken was surveyed during the geophysical and geological investigations directed by DR. M. N. HILL; the navigation was based mainly on dan buoys fitted with radar reflectors. The positions of the coring stations are given in Table 1. LAUGHTON (1960) has shown that Theta Gap at the south end of the Biscay abyssal plain is an interplain channel through which sediment can be transported to the Iberia plain. Mountains and abyssal hills protrude through this plain as parts of a topography which is largely buried and it is surrounded by abyssal hills and mountains to the west and south; it is bounded to the east by the continental slope of Spain and Portugal, (Deacon 1962, small scale illustration from an unpublished chart by LAUGHTON, 1959).

The sediments of this region are of two types. Those from the abyssal hills and mountains consist of foraminiferal oozes and brown lutites; the alternation of these oozes and lutites is illustrated by the variation in the calcium carbonate in the core 3738 (Fig. 1). The sediments from the abyssal plains consist principally of graded beds of sediment deposited by turbidity currents, which contain a suite of minerals 
The magnetization of sediment cores from the eastern basin of the North Atlantic Ocean 609

Table 1. Coring stations

\begin{tabular}{|c|c|c|c|c|}
\hline $\begin{array}{l}\text { Station } \\
\text { number }\end{array}$ & Latitude & Longitude & $\begin{array}{c}\text { Depth, } \\
\text { fm. } \\
\text { corrected }\end{array}$ & Region \\
\hline 3730 & $41^{\circ} 23^{\prime} \mathrm{N}$ & $14^{\circ} 23^{\prime} \mathrm{W}$ & 2920 & Iberia abyssal plain \\
\hline 3736 & 4100 & 1508 & 2893 & $\begin{array}{l}\text { Seamounts to the west of the } \\
\text { Iberia plain }\end{array}$ \\
\hline 3738 & 4100 & $15 \quad 08$ & 2880 & $\begin{array}{l}\text { Seamounts to the west of the } \\
\text { Iberia plain }\end{array}$ \\
\hline 3742 & $41 \quad 22$ & $14 \quad 32$ & 2919 & Iberia abyssal plain \\
\hline 3768 & $41 \quad 26$ & $14 \quad 41$ & 2872 & Bank rising from the Iberia plain \\
\hline 3780 & 4126 & $14 \quad 43$ & 2916 & Abyssal plain, foot of a bank \\
\hline 3781 & $41 \quad 27$ & $14 \quad 42$ & 2874 & Bank rising from the Iberia plain \\
\hline 3782 & 4101 & 1510 & 2837 & $\begin{array}{l}\text { Seamounts to the west of the } \\
\text { Iberia plain }\end{array}$ \\
\hline 4529 & 45 & 1128 & 2267 & Seamounts in the Biscay plain \\
\hline
\end{tabular}

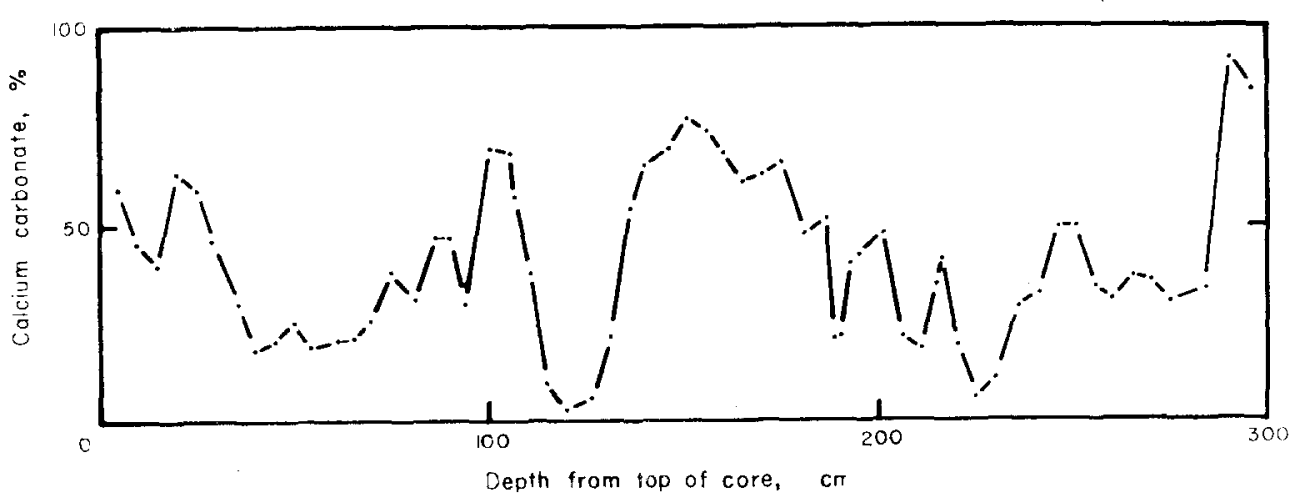

Fig. 1. Variations in the percentage of calcium carbonate in the core 3738 (Seamounts to west of Iberia plain).

usually associated with continental rocks and also contain a fauna composed of a mixture of planktonic and littoral organisms. Intercalated with the graded beds are pelagic sediments. Analyses which show the lithological characteristics of one of these abyssal plain cores (3742) are shown in Fig. 2, and a summary of its lithology is given in Table 2.

Table 2. Summary of lithology of the core 3742

\begin{tabular}{c|l}
\hline $0-26 \mathrm{~cm}$ & Brown pelagic sediment \\
$26-73 \mathrm{~cm}$ & Dark grey sediment-turbidity current deposit, sharp contact \\
$73-100 \mathrm{~cm}$ (approx.) & $\begin{array}{l}\text { Light grey, mottled, disturbed. Passes with no sharp contact into: } \\
\text { Dark grey sediment, becoming coarser down the core-- } \\
\text { turbidity current deposit. }\end{array}$ \\
\hline
\end{tabular}



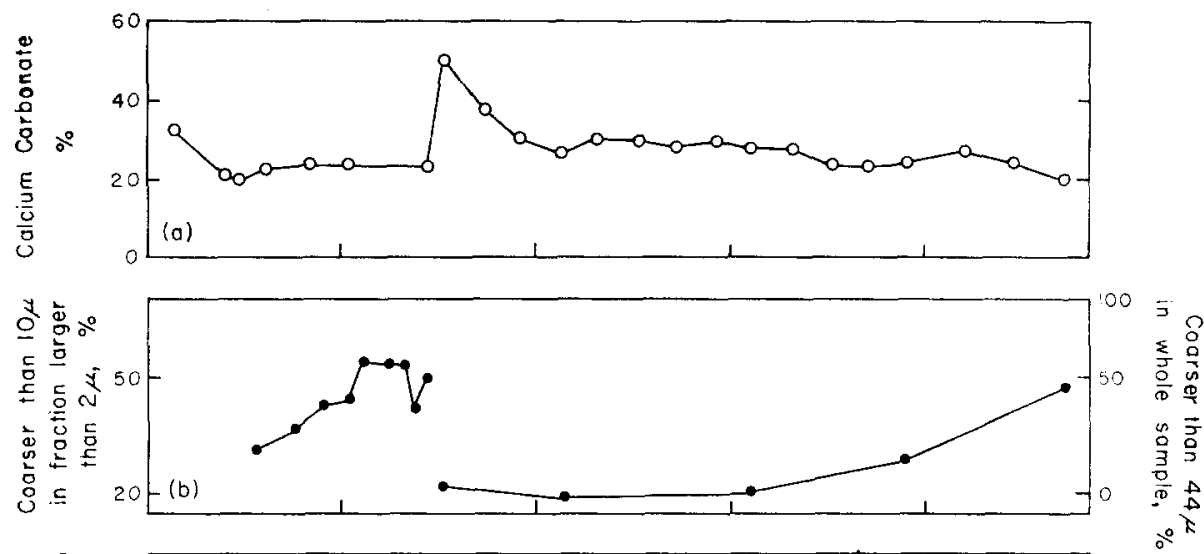

Boundaries

in core

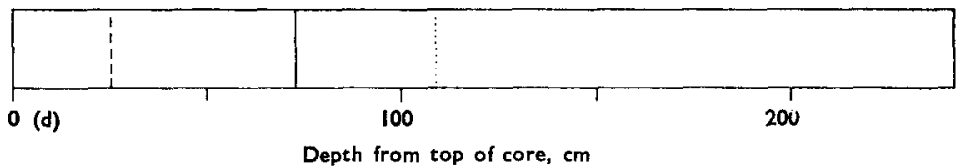

Depth from top of core, $\mathrm{cm}$

Fig. 2. Variations in calcium carbonate, size and water content with depth down the core 3742 (Iberia plain).

(a) Calcium carbonate as $\%$ of dry sediment.

(b) $0-73 \mathrm{~cm}$ (left hand ordinate) : Size analyses as \% of the material coarser than $10 \mu$ in the fraction larger than $2 \mu$ (a $140 \mu$ Coulter Counter tube was used).

$73-242 \mathrm{~cm}$ (right hand ordinate): Fraction of the whole sediment larger than $44 \mu$ (sieve analysis).

(c) Water content as \% of wet sediment. (d) Lithology-positions of contacts (see Table 2).

\section{Magnetic minerals}

\section{MAGNETIC PROPERTIES}

(i) Thermo-magnetic analyses:

Two types of investigations were made of the magnetic minerals in the sediment by thermomagnetic analysis. In one, the sediment was heated as a whole and its change in susceptibility with temperature was found on an a.c. bridge. In the other, magnetic concentrates were made and the Curie points were found on a Curie balance. The Curie points found in all the heating experiments of the whole sediment suggest that magnetite is the major constituent of the magnetic minerals in both the sediment from the abyssal plain cores and in the pelagic sediment from the surrounding banks. This conclusion is supported by $\mathrm{X}$-ray powder photographs.

(ii) Size analyses :

Sized fractions of sediment from the abyssal plain cores were prepared by sieving for sizes larger than $44 \mu$ and by decanting for sizes smaller than this. The sizes 
below $44 \mu$ to which reference is made are those appropriate for grains with a specific gravity of $2 \cdot 65$. The specific gravity of magnetite is $5 \cdot 2$ so that the grain sizes of the magnetite in the (22-44) $\mu$ fraction will be (14-28) $\mu$. The susceptibility of these sized fractions is shown in Fig. 3. This figure shows that the susceptibility reaches

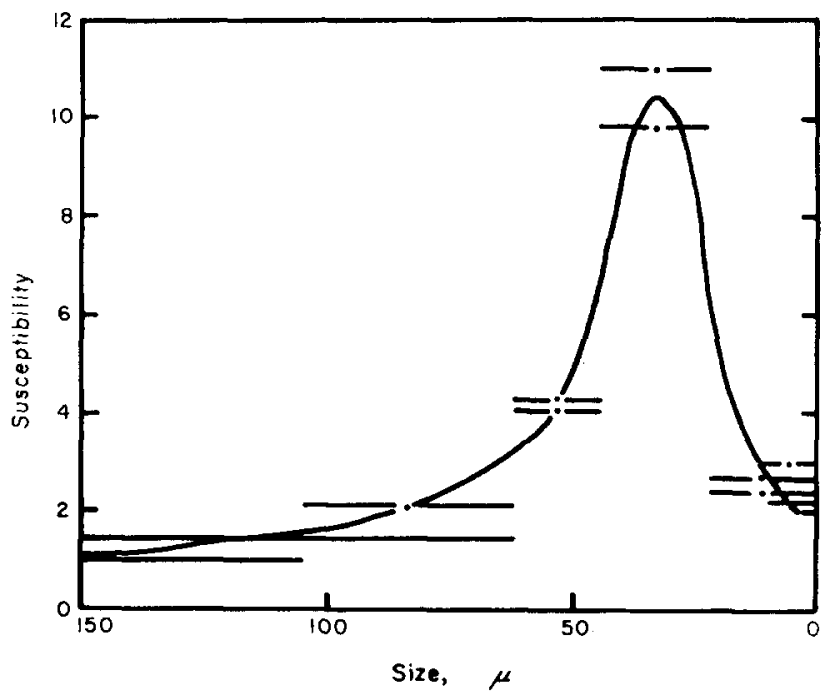

Fig. 3. Variations in the magnetic susceptibility in different size fractions of sediment from core 3730 (Iberia abyssal plain).

Magnetic susceptibility (e.m.u. $\mathrm{g}^{-1} \times 10^{-5}$ ) of dry sediment.

The lines show the limits of the size fractions; the dots (.) show the mid-points of the ranges except for size fractions in which there was no upper limit of size, such as fractions larger than $62 \mu$ and $105 \mu$.

a maximum value in the range 44 to $22 \mu$. Two fractions were taken from the sediment in core 3730 : one of the sediment greater in size than $62 \mu$ and the other $(44-22) \mu$. The susceptibility of the most pure magnetic concentrate that could be obtained from each size fraction was measured. The results are given in Table 3. These suggest that the increase in susceptibility shown in Fig. 3 is due to an increase

Table 3. Susceptibility of magnetic concentrates from core 3730

\begin{tabular}{|c|c|c|}
\hline & $\begin{array}{l}\text { Fraction larger than } \\
\qquad 62 \mu\end{array}$ & $\begin{array}{l}\text { Fraction } \\
(44-22) \mu\end{array}$ \\
\hline$\%$ magnetic separation by weight & $0 \cdot 15$ & $0 \cdot 47$ \\
\hline Magnetic susceptibility (e.m.u.g) ${ }^{-1}$ ) & $4.2 \times 10^{-3}$ & $1.2 \times 10^{-2}$ \\
\hline$\frac{\text { Susceptibility } \mathrm{g}^{-1}, 62 \mu}{\text { Susceptibility } \mathrm{g}^{-1},(44-22) \mu}$ & \multicolumn{2}{|c|}{13} \\
\hline
\end{tabular}

in the amount of magnetic material present; the amount in the $(44-22) \mu$ fraction is much larger than that in the fraction greater in size than $62 \mu$. Microscopical examination shows that the magnetic part of the fractions of smaller grain sizes consists of discrete grains of magnetic material whilst the magnetic part of the fractions 
of larger grain size consists of magnetic material as inclusions in other minerals and rocks. The susceptibility of the fraction (0-22) $\mu$ is low. NAGATA (1961) has shown that the susceptibility of titaniferous magnetite decreases with grain size, the effect being marked below about $100 \mu$. The amount of magnetic material present in the fraction (0-22) $\mu$ has not been determined but the low susceptibility of this fraction is as likely to be due to the intrinsic decrease in the susceptibility of magnetite with grain size, as it is to a decrease in the amount of magnetite that is present.

\section{Directions of magnetization}

The directions of magnetization of the two types of sediment that were discussed earlier are shown in Figs. 4-9. Figs. 4, 5 and 6 show the variations in the declination, $D^{\circ}$ about an arbitrary direction and the true values of inclination, $I^{\circ}$ of a number

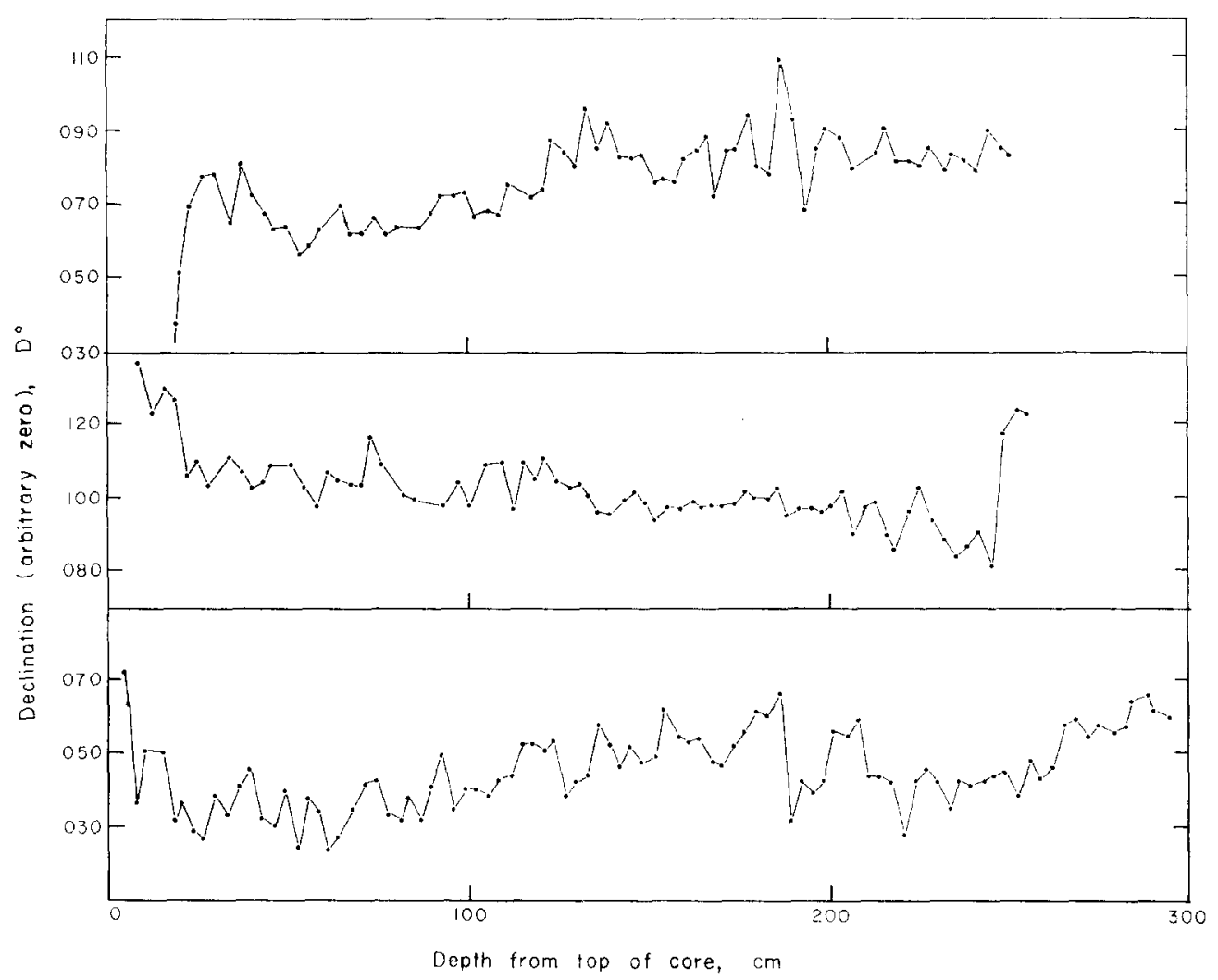

Fig. 4. Declination of non-abyssal plain cores; variation of declination, $D^{\circ}$ with depth (cm) in cores 3736 (top), 3738 (middle) and 3782 (bottom) (Seamounts west of Iberia plain). The values of $D^{\circ}$ are referred to arbitrary zeros.

of cores from the abyssal hills, and Figs. 7, 8 and 9 show the corresponding results for two abyssal plain cores. The accuracy of the measurements is approximately $\pm 5^{\circ}$.

These figures show a number of features : In the core 3742 (Fig. 7) the values of inclination in the sediment above the turbidity current deposits (i.e., from $0-29 \mathrm{~cm}$ and from $73-105 \mathrm{~cm}$ ) are near that of the ambient magnetic field which is about 


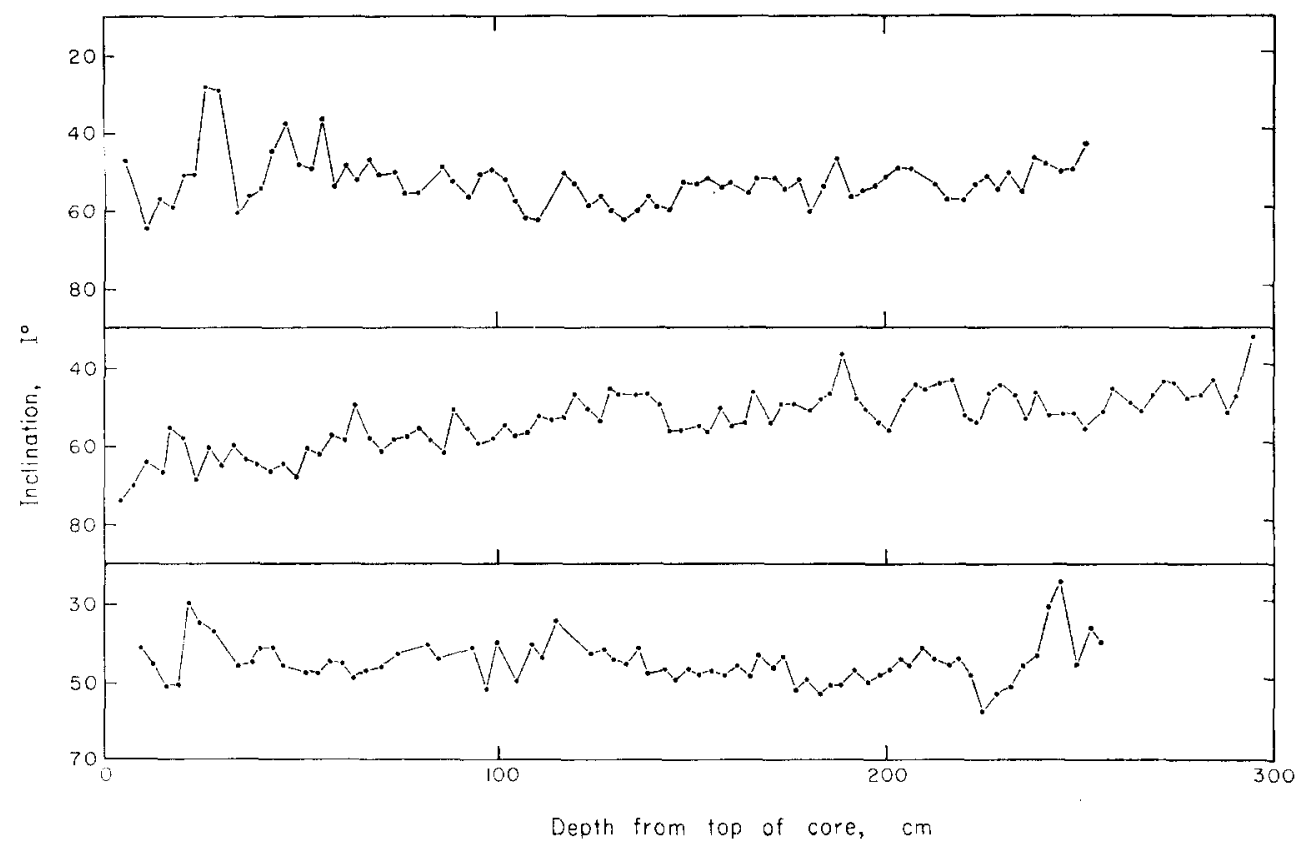

Fig. 5. Variation of inclination $I^{\circ}$ with depth (cm) in the cores 3736 (top), 3738 (middle), 3782 (bottom) (Seamounts west of Iberia plain). The values of $I^{\circ}$ have the horizontal as zero.
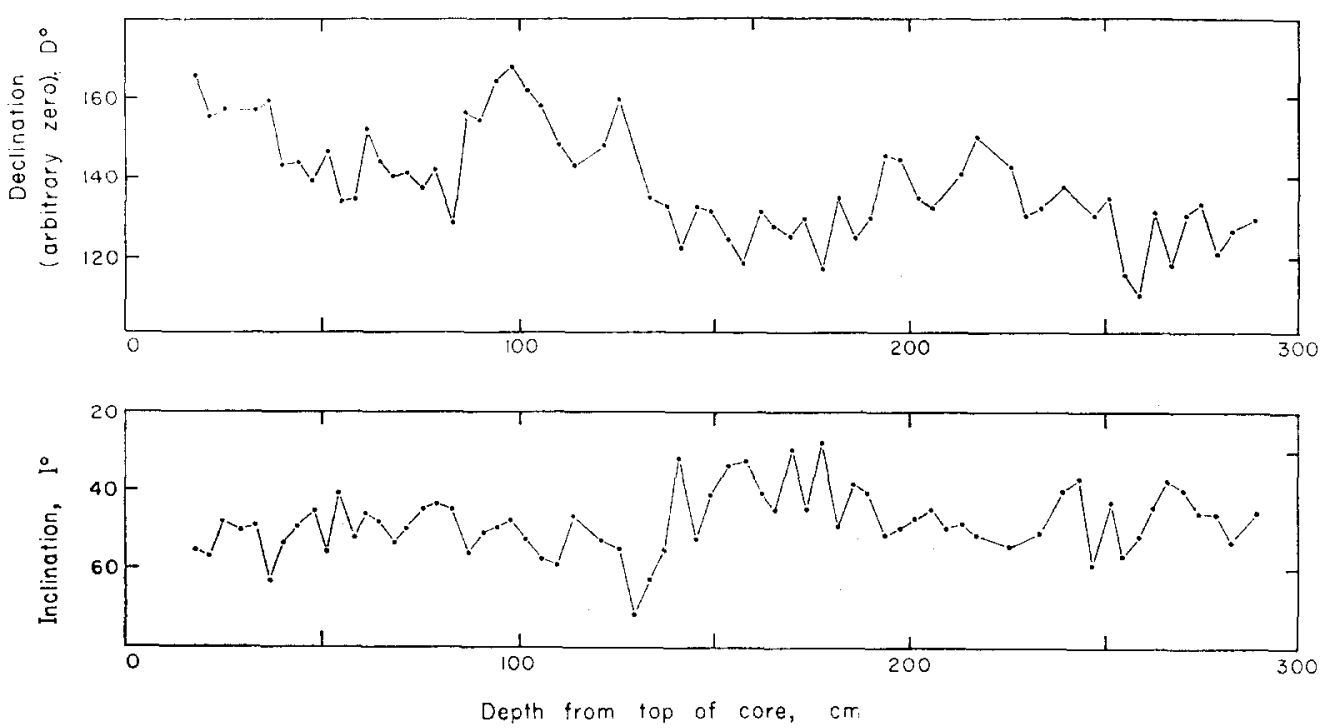

Fig. 6. Declination and inclination of non-abyssal plain cores.

(a) Variation of declination $D^{\circ}$ with depth $(\mathrm{cm})$ in the core 3781 (bank rising from Iberia plain).

(b) Variation of inclination $I^{\circ}$ with depth $(\mathrm{cm})$ in the core 3781 . The values of $D^{\circ}$ are referred to arbitrary zeros; the values. of $I^{\circ}$ have the horizontal as zero (see text). 
$55^{\circ}$ in this region of the Atlantic ocean. A similar feature can be seen in the core 3780 (Fig. 9). In those parts of the cores deposited by turbidity currents the inclination is shallow, and may reach values as low as $20^{\circ}$; such low values of inclination are seldom found in the wholly pelagic cores, such as in core 3738 (Fig. 5). The variation of the declination is large in the abyssal plain sediments; in any one turbidity current deposit such as that from $60-120 \mathrm{~cm}$ in 3780 (Fig. 8) the declination may vary by as much as $50^{\circ}$. Whilst in the non-abyssal plain cores the total variation from top to bottom of the cores may be as great as this (Figs. 4 and 6), there is no evidence that the changes in declination are dependent in so marked a way upon sedimentary features as they are in the abyssal plain cores.

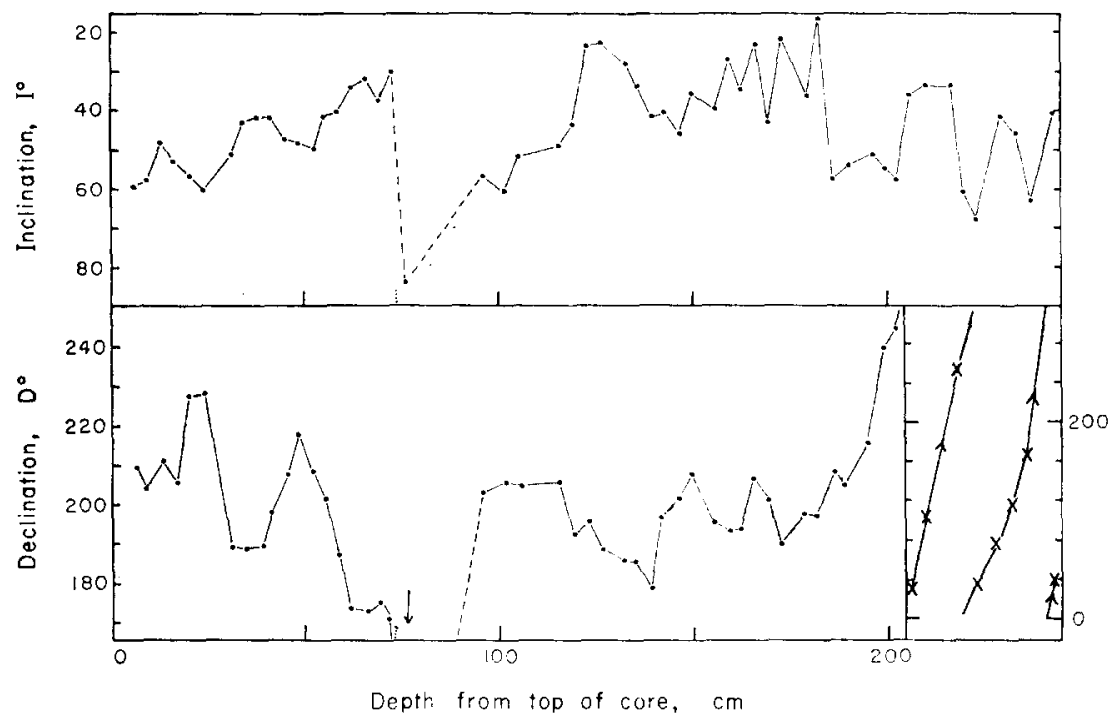

Fig. 7. Declination $D^{\circ}$ and inclination $I^{\circ}$ in an Iberia plain core 3742 . The values of $D^{\circ}$ are referred to an arbitrary zero; the values of $I^{\circ}$ have the horizontal as zero (see text). Note that there is a change in scale in values of $D^{\circ}$ at $204 \mathrm{cms}$. This figure should be compared with Fig. 2; the dots at $73 \mathrm{~cm}$ show the position of the sharp contact at the base of the upper graded bed. The arrow at $76 \mathrm{~cm}$ refers to a specimen in a disturbed part of the core, with a value of $D$ of $103^{\circ}$.

The directions of magnetization may be scattered in regions of the cores which are physically disturbed. This scatter can be seen at the tops of cores (Fig. 4) and in parts of the cores such as $3780(120-130 \mathrm{~cm})$ (Figs. 8 and 9) where a disturbance was observed after the core was sliced open. There is some evidence that the inclination in the non-abyssal plain cores such as 3738 and 3781 depends upon the water content. KEEN (1960) pointed out that the variation in the inclination and the variation in the water content of the core 3738 were similar and that both variations might be due to the consolidation of the sediment. Consolidation is difficult to estimate from any one core because lithological changes may produce gross fluctuations in the water content and obscure any variation due to consolidation. This difficulty can be overcome by finding the average water content at successive increments of depth from a number of cores, and BulLARD (1961) has shown that if this is done a decrease of water content with increasing depth is seen. There is not enough data available to 


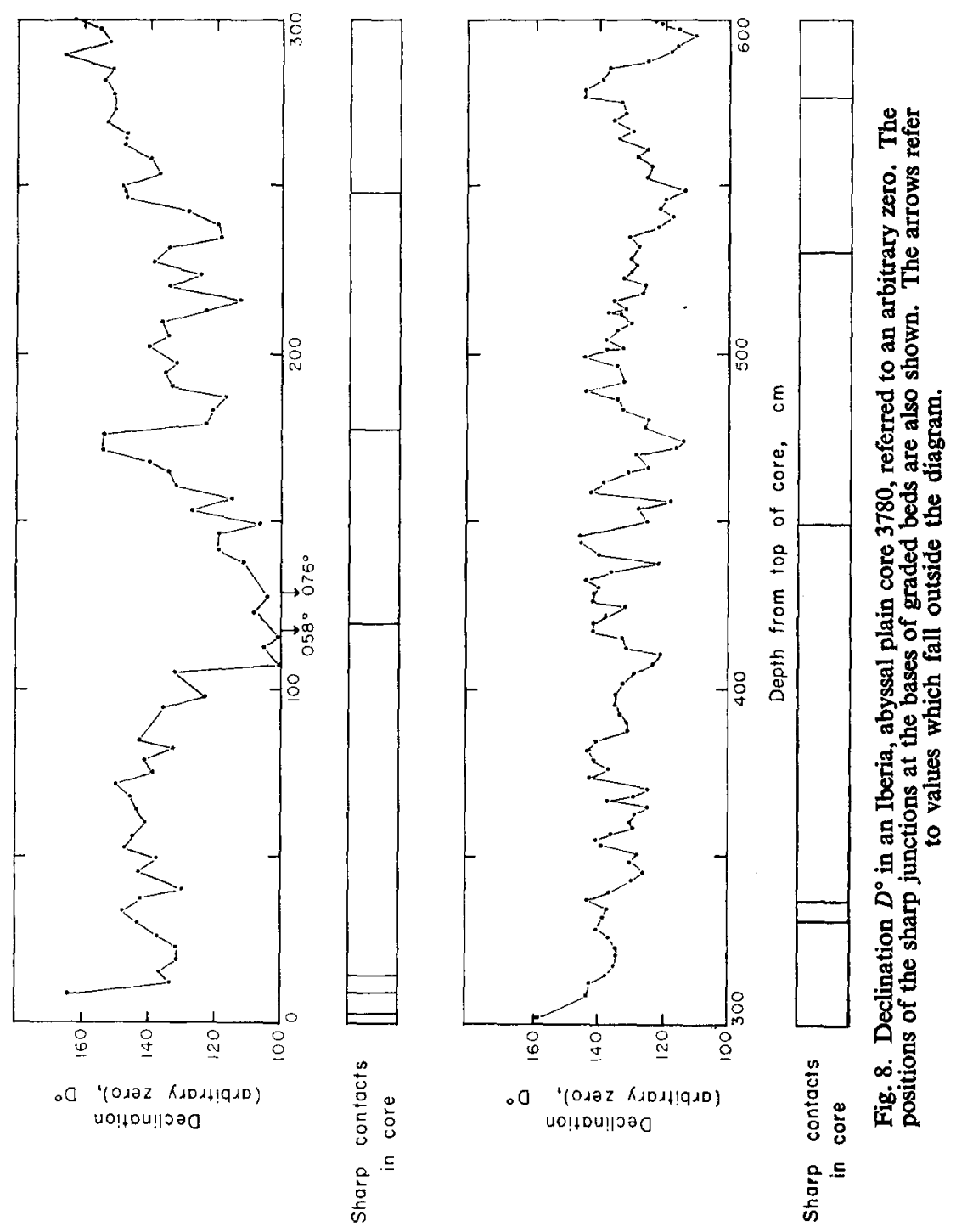



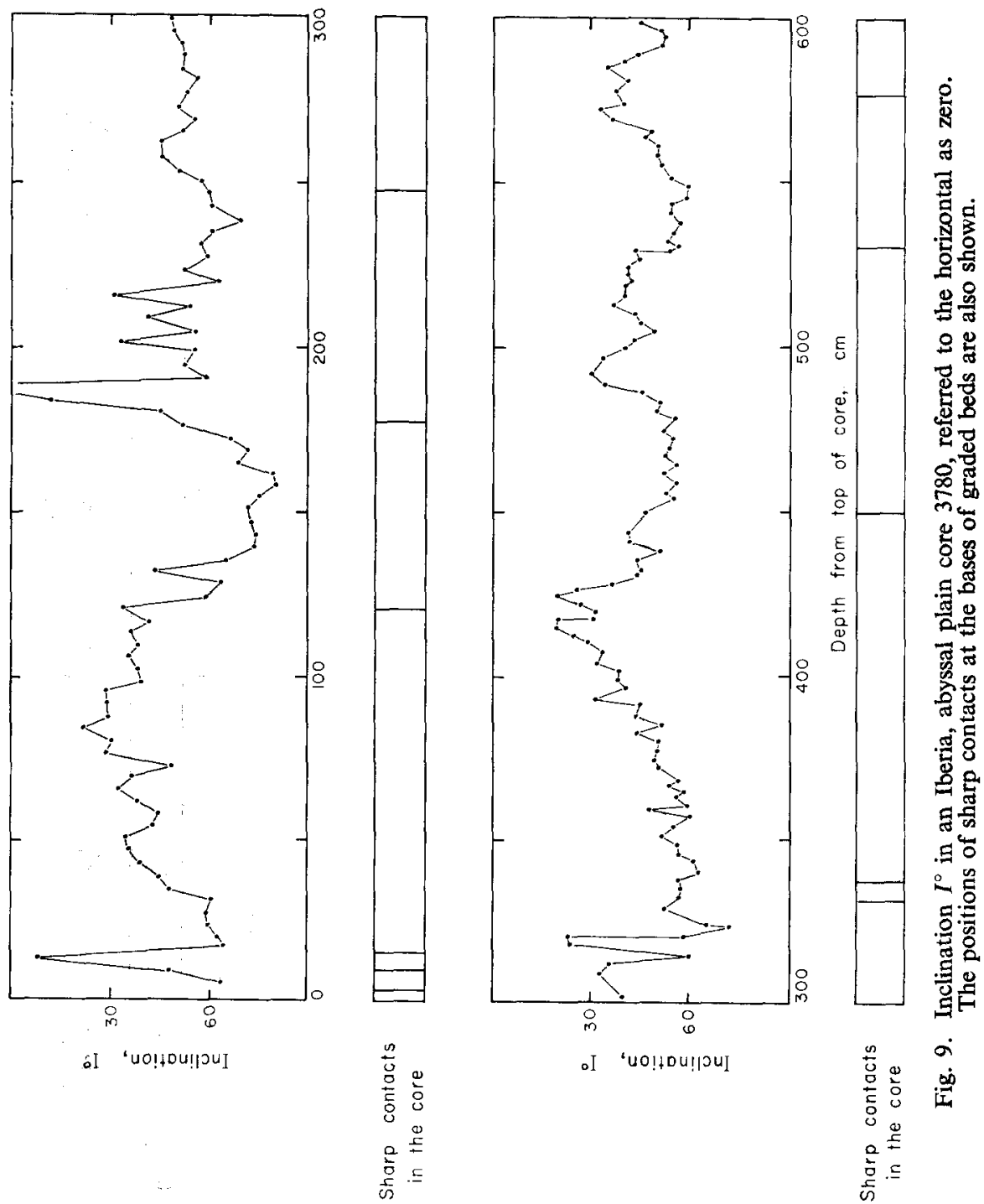
treat values of inclination in the same way and another approach to the problem is to investigate the relationship between the void ratio and the inclination in any particular core.

$$
\begin{aligned}
\text { Suppose } \mathrm{W} \text { per cent } & =\text { water content }=\text { (mass water/total mass }) \times 100 \\
\mathrm{e} & =\text { void ratio }=\text { volume of voids/volume of solids } \\
\mathrm{d} & =\text { density of solid constituents } \\
\text { then } \mathrm{e} & =100 \mathrm{~d} \mathrm{~W} /(100-\mathrm{W}) .
\end{aligned}
$$

Values of void ratio have been plotted against inclination for the core 3781 (Fig. 10); this figure shows that there may be some dependence of inclination upon the void ratio. Such a relationship could be due to consolidation. The same relationship holds for the core 3738 .

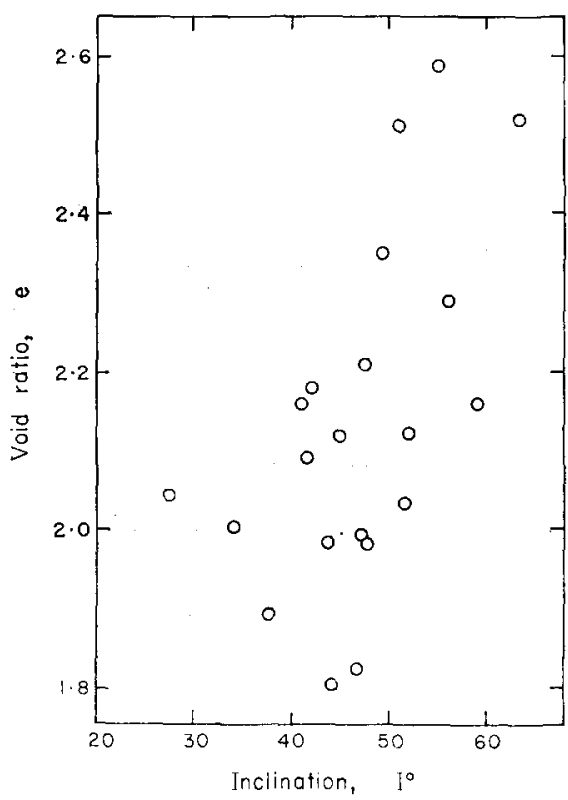

Fig. 10. Values of void ratio e plotted against corresponding values of inclination $I^{\circ}$ for the core 3781 .

If the variation in directions of magnetization in the non-abyssal plain cores were due only to changes in the Earth's magnetic field then there should be similar directions of remanent magnetization in those parts of different sediment cores which acquired their magnetization at the same time. Figures 4, 5 and 6 show that there is no similarity between the changes in the directions of magnetization in these cores. The cores 3736,3738 and 3782 were taken as close to one another as was possible by ordinary navigational methods. It is not possible to cross-correlate these cores on the basis of lithology with any certainty. However, any possible crosscorrelation on the basis of lithology or faunal changes cannot lead to similarity in the changes in the directions of magnetization. 


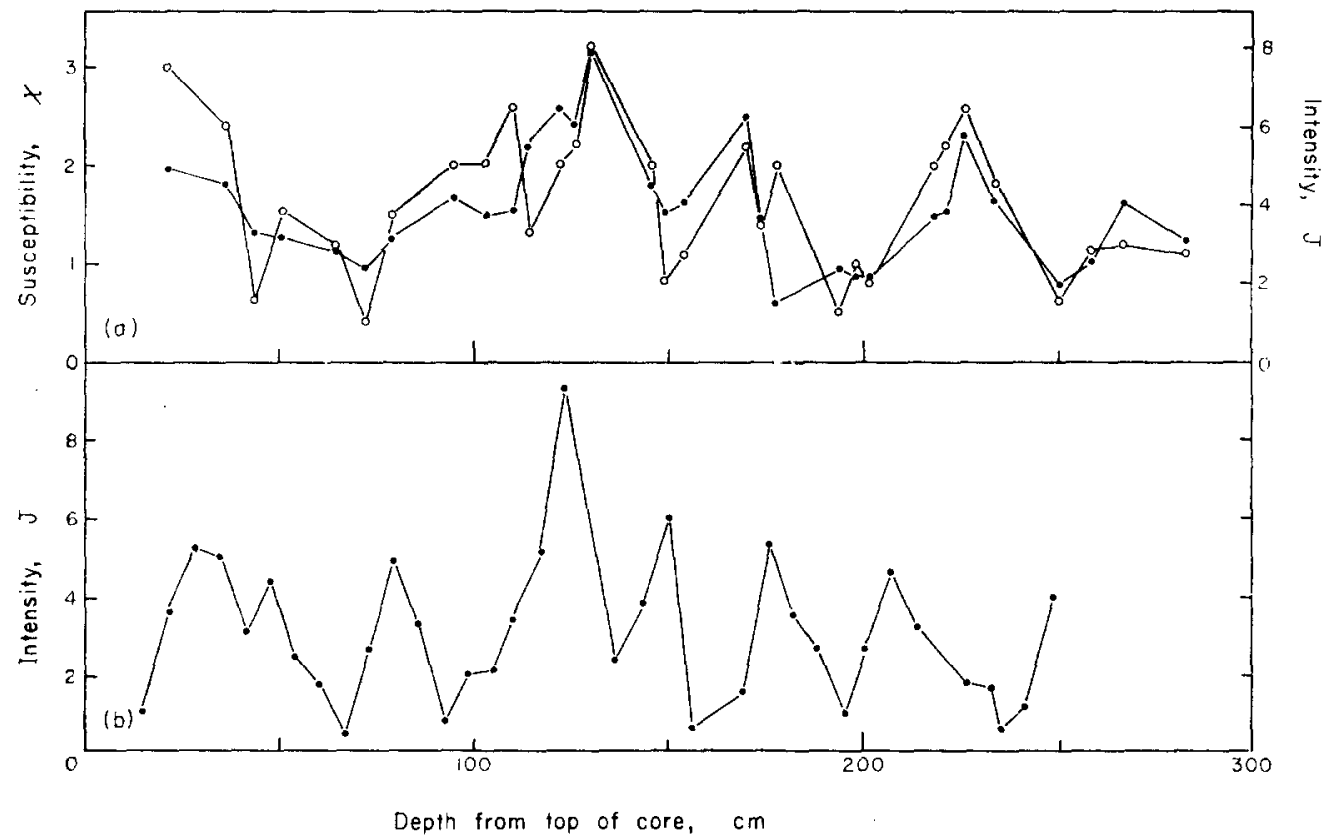

Fig. 11 (a). Core 3781 (Bank rising from Iberia plain) : variation of intensity of magnetization, $J$ (.) (relative values), and susceptibility, $\tau\left(^{\circ}\right)$ (e.m.u. $\mathrm{cm}^{-3} \times 10^{-5}$, wet sediment). (b) Core 3768 (same bank as 3781 ) : variation of intensity of magnetization, $J$ (relative values).

\section{Intensity of magnetization and magnetic susceptibility}

The intensity of magnetization, $J$. and the magnetic susceptibility, $x$ are shown in Figs. 11, 12 and 13 where the values are plotted against the depths in the cores. The values of $J$ and $x$ are of the order of $10^{-5}$ e.m.u. $\mathrm{cm}^{-3}$ for wet sediment; the type of variation of the values is different for the two groups, the abyssal plain sediments

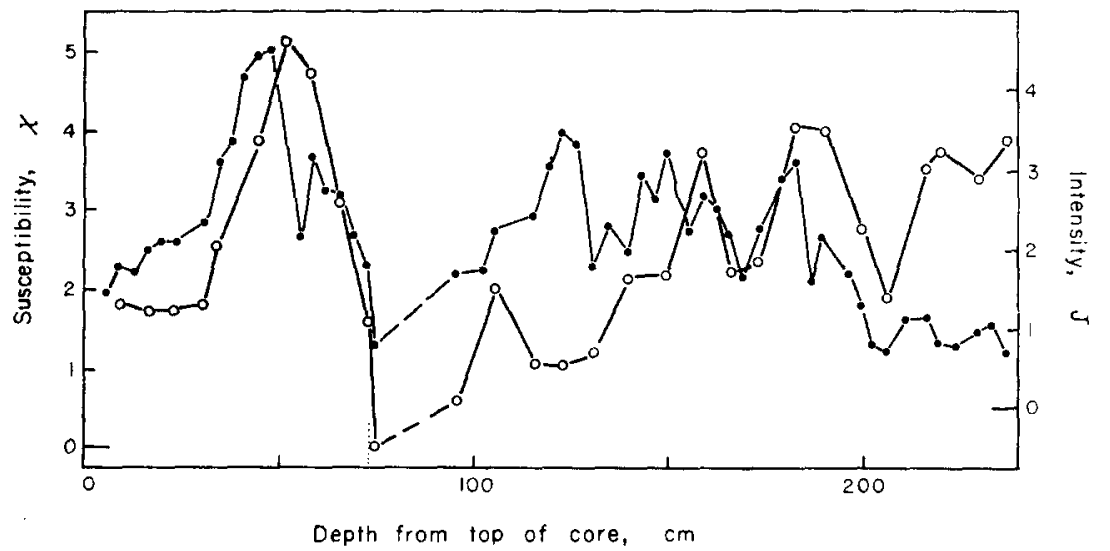

Fig. 12. Variation of intensity of magnetization and magnetic susceptibility of an abyssal plain core, 3742. The intensity is shown as (.) (relative values), and the susceptibility as $\left(^{\circ}\right)$ (e.m.u. $\mathrm{cm}^{-3} \times 10^{-5}$, wet sediment). 

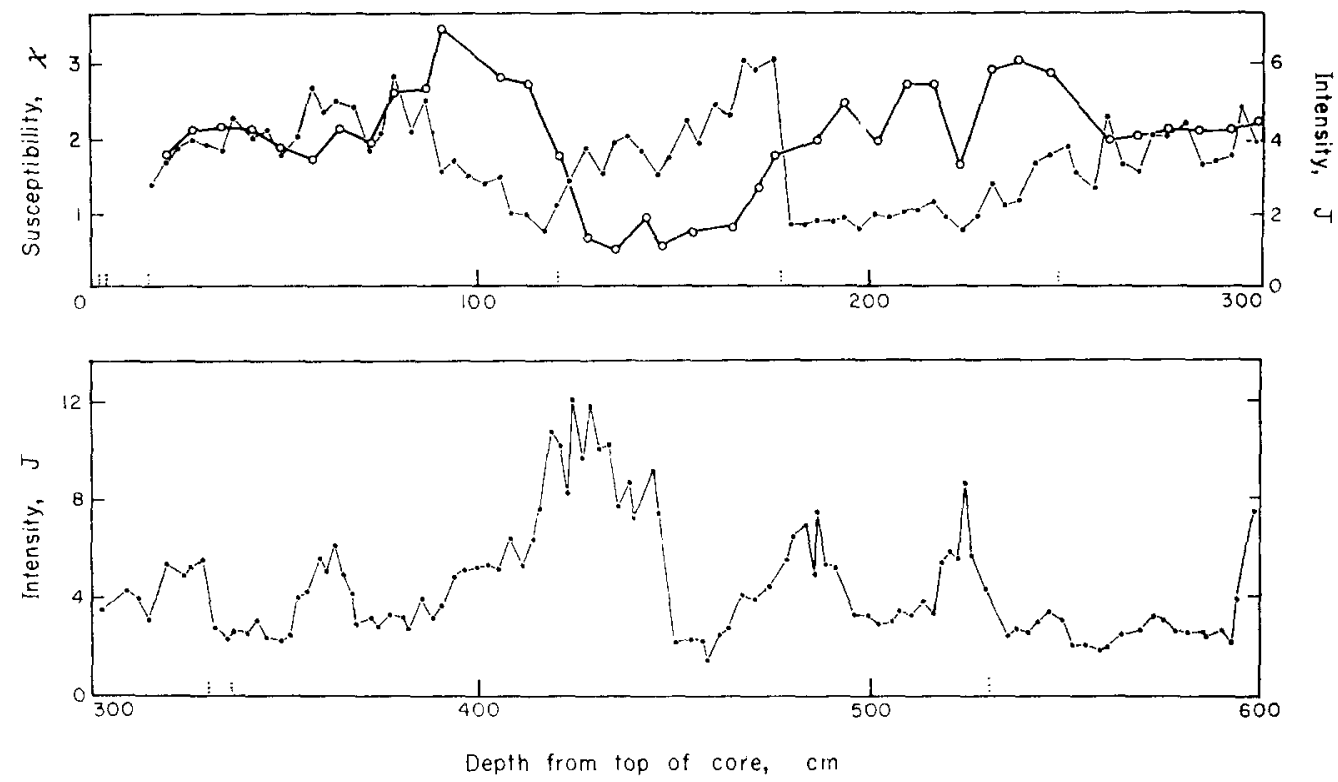

Fig. 13. Variation of intensity of magnetization and magnetic susceptibility of an abyssal plain core 3780 . The intensity is shown as (.) (relative values) and susceptibility as $\left(^{\circ}\right.$ ) (e.m.u. $\mathrm{cm}^{-3} \times 10^{-5}$, wet sediment).

and the non-abyssal plain sediments. The variation in the values of $J$ and $x$ in the non-abyssal plain cores, such as in $\mathbf{3 7 3 8}$ and $\mathbf{3 7 8 1}$ are similar, and statistical analysis with the values of $J$ and $x$ treated as a bivariate distribution shows that they are positively correlated and that the correlation is of high significance. They both vary directly with the percentage of the non-calcareous components of the sediment.

The variation is different in the abyssal plain sediments; in these the values of $J$ and $x$ are not always directly related and a statistical analysis of the values show that they have only a low correlation coefficient. The variation in the magnetic susceptibility is related to the size distribution of the magnetic material and to its abundance; this can be seen in $3742(29-73 \mathrm{~cm})$. The susceptibility and the grain size both increase with depth in the upper part of this turbidity current deposit but in the lower part, although the grain size does not decrease in any marked way, the values of susceptibility fall sharply (Figs. 2 and 12). These effects are explained by the results which have been discussed already; if the grain size is small then the susceptibility is low, and if the grain size is large the content of magnetic minerals is small.

\section{STABILITY OF MAGNETIZATION}

Tests for stability of magnetization did not give unambiguous answers : a high degree of stability of magnetization was suggested by results of alternating current demagnetization, by storage tests and by the consistency of the results. Stability would also be suggested by a change in inclination with consolidation; the relationship between inclination and void ratio may be real and might be explained by consolidation. The dependence of the directions of magnetization upon sedimentary 
features in those parts of the abyssal plain cores deposited by turbidity currents also suggests stability. Further evidence for stability is that where there is physical disturbance, such as is usual at the tops of cores and such as that in $3780(120-130 \mathrm{~cm}$, Fig. 9), the directions of magnetization are also disturbed. However, the results from one core cast doubt upon the magnetic stability.

One core, 4529 , was taken from mountains rising out of the Biscay abyssal plain. This core gave the opportunity to apply a test akin to the 'fold' test described by GRAHAM (1949). It consists of disturbed sediment lying on top of apparently undisturbed, horizontally bedded sediment; there is no undisturbed sediment above the disturbed part. The characteristics of the disturbance are unlike those seen when sediment is 'sucked in' to the core barrel; when this occurs the disturbance consists of sediment streaked out longitudinally. It seems possible that the disturbance is due to slumping.

The measurements of the directions of magnetization did not satisfy the criteria for stability demanded by the "fold 'test. The scatter of the directions in the disturbed region is not especially large and if a correction is made for the tilt of the beds the directions which result are far from those of samples from the undisturbed region; the inclination of these samples is consistent with that of the present field.

The obvious conclusion to be drawn from this is that the sediment is magnetically unstable; this apparent instability may however be a phenomenon peculiar to slumped beds in that, during slumping the sediment may be sufficiently fluid that reorientation of the magnetic particles occurs.

\section{DISCUSSION}

The principal features of the magnetization of the sediment cores are these. The mineral responsible for the magnetization appears to be magnetite, which is likely to have a detrital origin in both the abyssal hill cores and the abyssal plain cores. The direction and the intensity of magnetization has different characteristics in the two types of core. Stability of magnetization is indicated in the abyssal plain cores because the inclination of the remanent magnetization is low; if the effect of consolidation upon inclination is a real one, stability is suggested in the non-abyssal plain cores. In one core, 4529 , measurements in a slumped bed suggest either instability or reorientation of the magnetic particles during slumping. No correlation has been found between cores of sediment taken close together.

GRIFFITHS and others (1960) and REES (1961) have shown that there are two principal effects to be seen in sediment from varved clays which is re-deposited under controlled conditions in the laboratory. The angle of inclination of the remanent magnetization of sediment re-deposited on a horizontal surface was lower than that of the ambient field by values up to about $20^{\circ}$. The effect of currents in water during sedimentation was primarily to alter the declination by up to about $20^{\circ}$. The sediment was deposited at a rate of 1 or $2 \mathrm{~cm}$ in times ranging from a few days to a few months and the currents used were in the range of a few centimetres per second. These conditions are like those to be expected when the sediment from a turbidity current settles out, for the time that the sediment will take to settle out completely will range up to several years and there may be currents in the water of a few centimetres per second during this settling out. The same effects that were 
observed by GRIFFTHS and by REES are observed in the turbidity-current-deposited sediment, in particular low inclinations and variable declinations. By contrast with abyssal plain sediment the inclination in the cores from areas off the plain is much less variable and is always about the same as that of the ambient field, except for the possible small consolidation effect. The declination only varies over a comparatively long length of core and the variation is not related to sedimentary features in any obvious way. The conditions under which the pelagic sediment is deposited is completely different from that of the abyssal plain sediment. The deposition is continuously slow and may be of the order of $2 \mathrm{~cm}$ per thousand years. Disturbing influences will be bottom currents in the water and burrowing in the sediment. The burrowing is such that the sediment will be continuously disturbed to depths of 5 or $10 \mathrm{~cm}$ below the sediment-water interface and it is possible that if a stable direction of remanent magnetization is ever acquired then it is only acquired finally when the sediment is no longer affected by burrowing. These considerations will apply not only to the whole of the sediment in the cores from areas away from the abyssal plains but also to the pelagic sediment between or above the sediment deposited by turbidity currents in the abyssal plain cores.

The magnetic minerals appear to be magnetite and some of this occurs as inclusions in fragments of igneous rocks; this makes it likely that the magnetization is due to the orientation of detrital magnetic grains, and that it is not a chemical magnetization. Iron-manganese oxides occur in these Atlantic sediments but they cannot affect the overall magnetization since the concentration is too low and the susceptibility of these oxides is of the order of $10^{-5}$ e.m.u. $\mathrm{g}^{-1}$.

The secular variation of the Earth's magnetic field has a time scale of a few hundreds of years and shows ranges in values of declination and inclination of about $40^{\circ}$ and $20^{\circ}$ respectively. A variation on a time scale longer than this would be recorded in the sediments from the areas off the abyssal plains. The rate of sedimentation is relatively low and the size of samples relatively large, but the extent of burrowing in these cores of sediment is such that the remanent magnetization would reflect a field averaged over a longer time than is represented by the dimensions of the samples. However, no claim can be made yet that the remanent magnetization of the sediment cores gives a true value of the direction of the Earth's field because no correlation has been obtained between the directions of magnetization of neighbouring cores and because one core, 4529, suggests some form of instability.

Acknowledgements-I should like to thank Dr. M. N. Hill, Dr. J. C. BelSHÉ, Dr. J. E. Blanchard, Dr. M. D. Fuller, Dr. B. M. FunNell and Dr. A. S. Laughton for their help and advice, the Royal Dutch-Shell Group of Companies for a Studentship, and British Petroleum for a Fellowship. I thank, too, the officers and crew of R.R.S. Discovery $I I$ for their assistance; without their help this study would have been impossible.

\section{REFERENCES}

Bullard E. C. (1961) The flow of heat through the floor of the Atlantic Ocean. Geophys. $J$. 4, $282-292$.

Davmoson C. E. and KeEn M. J. (1963) Size analyses of turbidity current sediment. Nature, Lond. 197, 372-373.

Deacon G. E. R. (1962) Navigation and the science of the sea. J. Inst. Nav. 15, 1-13.

FunNell B. M. (1960) Personal communication.

GraHAm J. W. (1949) The stability and significance of magnetism in sedimentary rocks. J. Geophys. Res. 54, 131-168. 
Granar L. (1959) Magnetic measurements on Swedish varved sediments. Ark. geofys. 3, $1-96$.

Griffiths D. H., King R. F., Rees A. I. and Wright A. E. (1960) The remanent magnetism of some recent varved sediments. Proc. Roy. Soc. Lond. A, 256, 359-383.

IsING G. (1943) On the magnetic properties of varved clay. Ark. mat. astron. fys. 29, A, No. 5.

JoHnson E. A., MUrPHY T. and Torreson O. W. (1948) Prehistory of the Earth's magnetic field. Terr. Magn. Atmos. Elec. 53, 349-372.

KEEN M. J. (1960) Magnetization of sediment cores from the eastern Atlantic Ocean. Nature, Lond. 187, 220-222.

Laughton A. S. (1959) Chart of the Central part of the Iberian abyssal plain centred on Swallow Bank. Nat. Inst. Oceanogr., England (unpublished).

Laughton A. S. (1960) An interplain deep-sea channel system. Deep-Sea Res. 7, 75-88.

McNish A. G. and Johnson E. A. (1939) Determination of secular variation in New England from magnetic polarisation of glacial varves. Internat. Ass. Terr. Magn. Elect., Washington.

NaGATA T. (1961) Rock Magnetism, Fig. 3-20, p. 99. Maruzen, Tokyo.

REES A. E. (1961) The effect of water currents on the magnetic remanence and anistropy of susceptibility of some sediments. Geophys. J. 5, 235-251. 